\title{
Heat transfer and nanofluids flow through the circular concentric heat pipes: a comparative study using least square method (LSM)
}

\author{
M. Hatami ${ }^{a, b}$, S. Mosayebidorcheh ${ }^{c}$, J. Geng $^{a}$, D. Jing ${ }^{a, *}$ \\ ${ }^{a}$ International Research Center for Renewable Energy, State Key Laboratory of Multiphase Flow in Power Engineering, Xian Jiaotong \\ University, Xian 710049, China. \\ ${ }^{b}$ Department of Mechanical Engineering, Esfarayen University of Technology, Esfarayen, North Khorasan, Iran. \\ ${ }^{c}$ Department of Mechanical Engineering, Khomeinishahr Branch, Islamic Azad University, Khomeinishahr, Iran.
}

\begin{abstract}
In this paper, hydro-thermally performance of a circular concentric heat pipe is evaluated using the analytical least square method (LSM) and the accuracy of results is examined by fourth order Runge-kutta numerical method. In described problem, the pipe walls are permitted to carry different and opposite slip velocities of nanouids and they are either preserved at constant heat flux of outer wall with the inner wall insulated or vice versa. For this study, five distinct types of nanoparticles: $\mathrm{Ag}$, Cu, Cuo, $\mathrm{Al}_{2} \mathrm{O}_{3}$ and $\mathrm{TiO}_{2}$ are considered in the water base fluid and the results of velocity profiles and Nusselt numbers in different slip conditions were presented and discussed. As a main result, by decreasing the distance between the pipes, more heat will transfer to nanofluids from the wall under the heat flux, so it makes larger Nusselt number. (C)2017 All rights reserved.
\end{abstract}

Keywords: Heat pipe, nanofluid, Nusselt number, LSM.

2010 MSC: 80A99, 65L06, 93E24.

\section{Introduction}

Nowadays, heat pipes, simple devices used to transfer the heat from one place to the other, find numerous applications such as in solar energy, air conditioning systems, and waste heat recovery to save energy and prevent global warming. Heat pipes applications can be divided into three main categories: separation of heat source and sink, temperature equalization, and temperature control. Due to their extremely high thermal conductivity, heat pipes can efficiently transport heat from a concentrated source to a remotely mounted sink. This property can enable dense packing of electronics, for example, without undue regard for heat sink space requirements.

Nanofluids are another most important topics of heat transfer enhancement due to their high application in industry and technology to facilitate the heat transfer phenomena [31]. Rana et al. [35] investigated the flow and heat transfer of a nanofluid over a nonlinearly stretching sheet by numerical solution. After that, Rashidi et al. [36] considered the nanofluid flow over a stretching porous plate and analyzed it by analytical method. Also, magnetohydrodynamic squeezing flow of a viscous fluid between parallel disks was analyzed by Domairry and Aziz [9]. The nanouid slip flow within circular concentric pipes has

\footnotetext{
*Corresponding author

Email addresses: m.hatami2010@gmail.com (M. Hatami), dwjing@mail.xjtu.edu.cn (D. Jing)
} 
been theoretically investigated in the presence of thermal conditions of either constant heat flux at the outer wall and the inner wall insulated or vice versa by Turkyilmazoglu [39]. In another study, Turkyilmazoglu [38] solved momentum and energy equations of nanofluids analytically to deduce the flow and heat transport phenomena in two theoretical cases, single phase and multi-phase. When the nanoparticles are uniformly distributed across the condensate boundary layer called it single phase and when the concentration of nanoparticles through the film is allowed to vary from the wall to the outer edge of the condensate film in the light of modified Buongiorno's nanofluid model named multi-phase. Solution of particle's motion in different fluids media has been considered by the authors widely [8, 22, 24, 25].

Comparison of the single and two-phase modeling for the nanofluids has been considered by the researchers. For instance, Haghshenas Fard et al. [20] compared the results of the single phase and twophase numerical methods for nanofluids in a circular tube. They reported that for Cu-water the average relative error between experimental data and CFD results based on single-phase model was $16 \%$ while for two-phase model was $8 \%$. In another numerical study, Gktepe et al. [19] compared these two models for nanofluid convection at the entrance of a uniformly heated tube which found the same results and confirmed the accuracy of two-phase modeling. Mohyud-Din et al. [33] in an analytical study, considered the three dimensional heat and mass transfer with magnetic effects for the flow of a nanofluid between two parallel plates in a rotating system. As one of their main outcomes, thermophoresis and Brownian motion parameters are directly related to heat transfer but are inversely related to concentration profile. Also they found that the higher Coriolis forces decrease the temperature boundary layer thickness. Threedimensional flow of nanofluids under the radiation (due to solar or etc.) has been analyzed by Hayat et al. [29] and Khan et al. [30]. They also computed and examined the effects of different parameters on the velocity, temperature, skin friction coefficient, and Nusselt number of nanofluid flow. Other works of nanofluids flow and heat transfer analysis can be found in $[1,10,13,15,17,26,28]$.

Ozisik [34] introduced some simple and accurate approximation techniques for solving nonlinear differential equations called the weighted residual methods such as collocation, Galerkin and least square method (LSM) for heat transfer problems. Stern and Rasmussen [37] used collocation method for solving a third order linear differential equation. Vaferi et al. [40] have studied the feasibility of applying of orthogonal collocation method to solve diffusivity equation in the radial transient flow system. Recently Hatami and Ganji [27] used LSM for heat transfer study through porous fins also they used this accurate method for fully wet circular porous fin [23], semi-spherical porous fins [21], and straight solid and porous fins [18]. Gao and Duan [14] developed and analyzed least-squares approximations for the incompressible magneto-hydrodynamic equations. Ghasemi et al. [16] found that LSM is more appropriate than other analytical methods for solving the nonlinear heat transfer equations. Bhatti et al. [4-6] used different numerical and analytical methods for analysis the nanofluids treatment in various geometries. Bovand et al. [7] applied the Eulerian-Lagrangian model for particles transport study in a duct to investigate the effect of trap and reflect boundary conditions. Laein et al. [32] in an experimental study, investigated the free convection of nanofluids in horizontal and vertical plates while Akbarzadeh et al. [3] focused on the pumping power of nanofluids in a wavy channel. There are more valuable studies in the nanofluids criteria have done by Ellahi et al. $[2,11,12]$ to investigate the effects of aggregations, size and shapes of nanoparticles. Based on above short review, the aim of present paper is to extend the work by Turkyilmazoglu [39] for a concentric heated pipe where the walls are permitted to carry different and opposite slip velocities using analytical LSM method.

\section{Problem description}

Consider the hydro-dynamically and thermally fully developed water-based nanofluids flowing through circular concentric heat pipe as displayed in Fig. 1. As shown in this figure, the r-axis is considered normal to the pipe walls and the x-axis is aligned horizontally, the inner and outer pipe radii named as $r_{i}$ and $r_{o}$, respectively and the walls of the pipe are permitted to carry different and opposite slip velocities of nanofluids and they are either preserved at constant heat flux q of outer wall with the 
inner wall insulated, or the outer wall at adiabatic wall condition while inner wall subjected to a constant wall heat flux q. The motion is due to a constant pressure gradient with respect to x-coordinate.

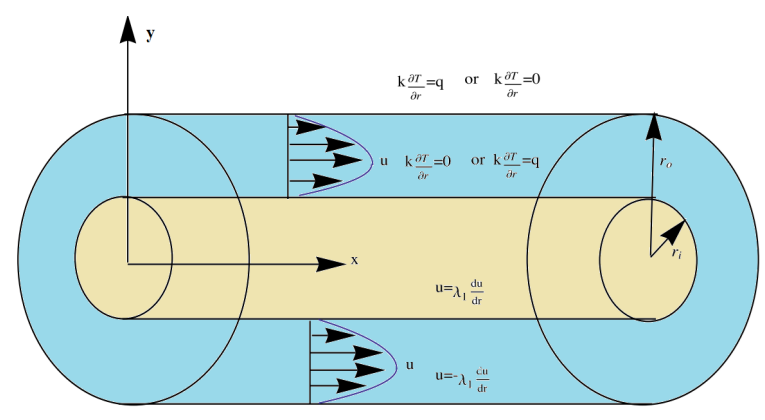

Figure 1: Schematic of the problem [39].
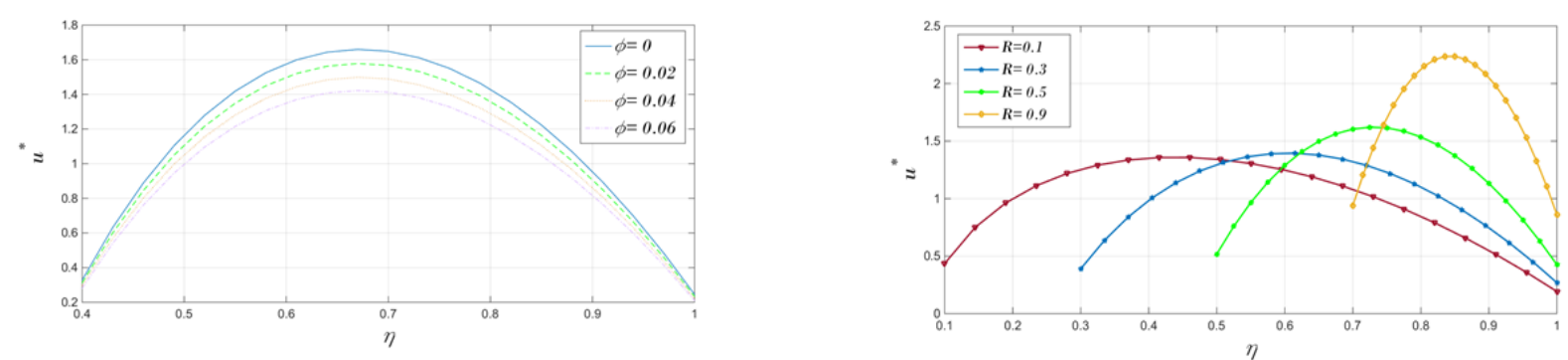

Figure 2: $u^{*}$ profile for cu-water nanofluid in different Figure 3: $u^{*}$ profile for cu-water nanofluid in different $\mathrm{R}$ and nanoparticles volume fraction and $\lambda_{1}=\lambda_{2}=0.03, R=0.4 . \quad \lambda_{1}=\lambda_{2}=0.05, \phi=0.03$.

Table 1: Physical properties of base fluid and nanoparticles [39].

\begin{tabular}{lcccc}
\hline & $\rho\left(\frac{\mathrm{kg}}{\mathrm{m}^{3}}\right)$ & $\mathrm{C}_{\mathrm{p}}\left(\frac{\mathrm{J}}{\mathrm{kgK}}\right)$ & $\mathrm{k}\left(\frac{\mathrm{W}}{\mathrm{mK}}\right)$ & $\beta \times 10^{5}\left(\mathrm{~K}^{-1}\right)$ \\
\hline Water & 997.1 & 4179 & 0.601 & 21 \\
$\mathrm{Cu}$ & 8933 & 385 & 401 & 1.67 \\
$\mathrm{CuO}$ & 6320 & 531.8 & 76.5 & 1.80 \\
$\mathrm{Ag}$ & 10500 & 235 & 429 & 1.89 \\
$\mathrm{Al}_{2} \mathrm{O}_{3}$ & 3970 & 765 & 40 & 0.85 \\
$\mathrm{TiO}_{2}$ & 4250 & 686.2 & 8.9538 & 0.9 \\
\hline
\end{tabular}

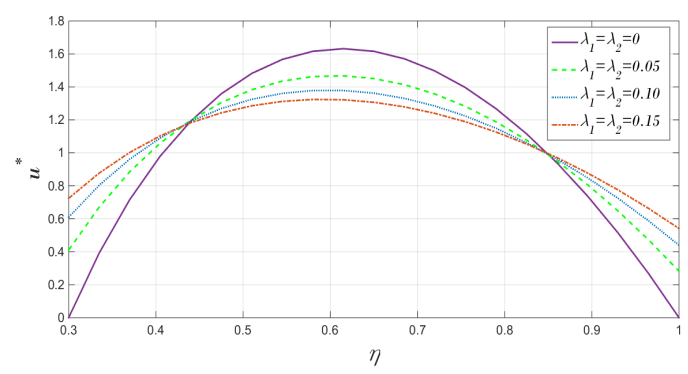

Figure 4: $u^{*}$ profile for cu-water nanofluid in different $\lambda$ and $\mathrm{R}=0.3, \phi=0.02$.

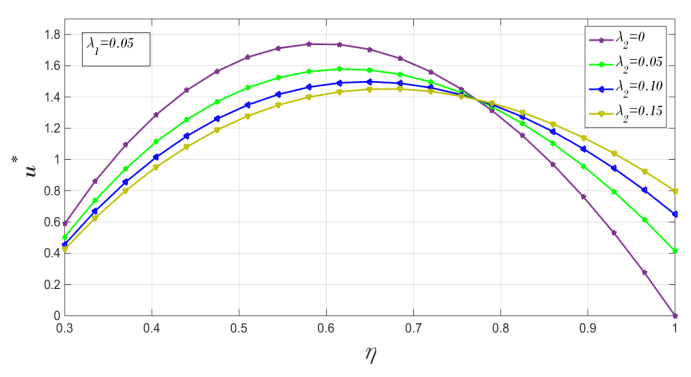

Figure 5: $\mathrm{u}^{*}$ profile for $\mathrm{cu}$-water nanofluid in different $\lambda_{2}$ and $R=0.5, \phi=0.04$. 

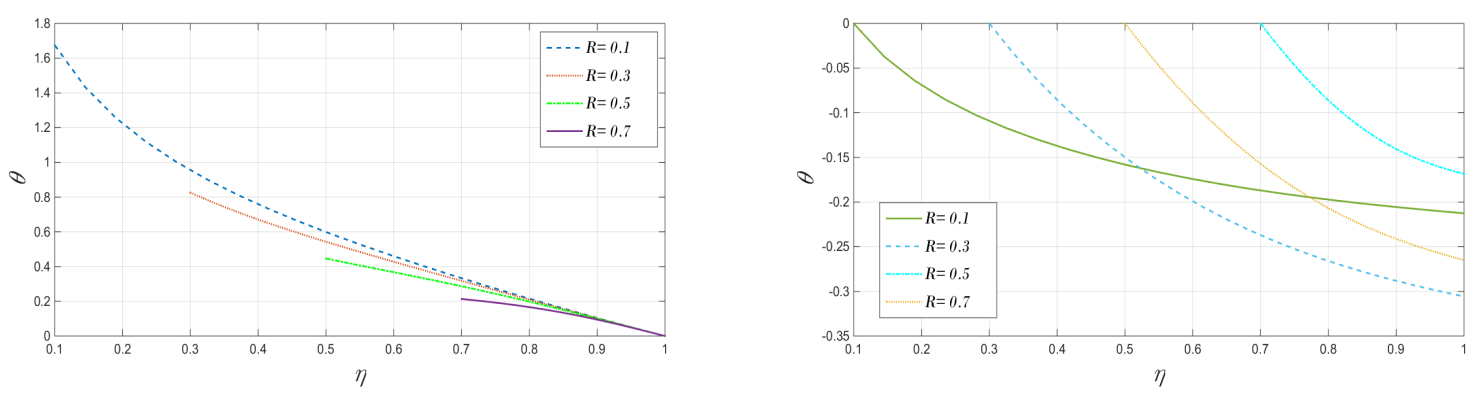

Figure 6: Temperature profile when $\lambda_{1}=\lambda_{2}=0.04, \phi=0.03$, $\mathrm{Cu}$ for (a) constant outer heat flux $\alpha=-\beta=-1$ and (b) constant inner heat flux $\alpha=\beta=R$.
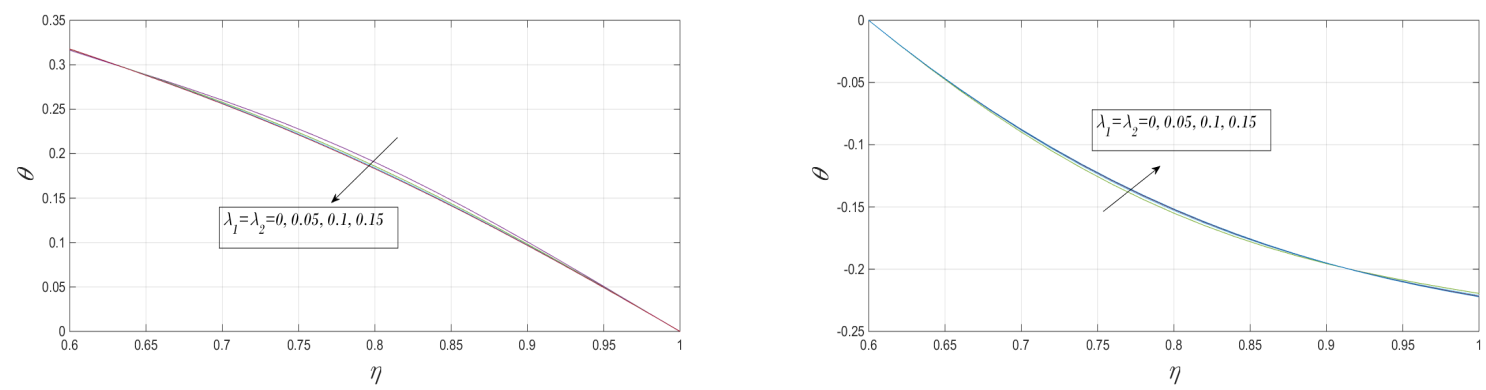

Figure 7: Temperature profile when $\mathrm{R}=0.6, \phi=0.05, \mathrm{Al}_{2} \mathrm{O}_{3}$ for (a) constant outer heat flux $\alpha=-\beta=-1$ and (b) constant inner heat flux $\alpha=\beta=$ R.
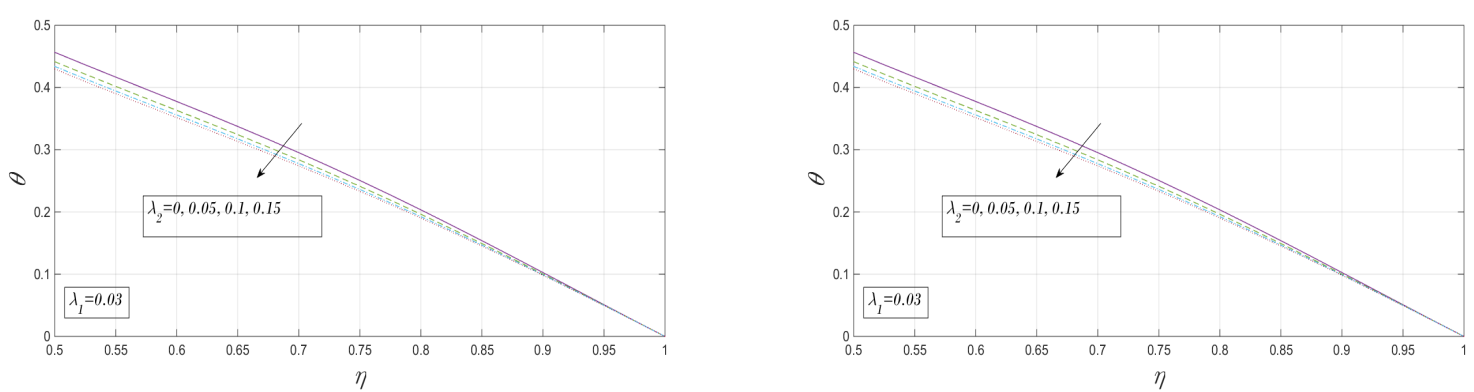

Figure 8: Temperature profile when $\lambda_{1}=0.03, \phi=0.02, \mathrm{R}=0.5, \mathrm{TiO}_{2}$ for (a) constant outer heat flux $\alpha=-\beta=-1$ and (b) constant inner heat flux $\alpha=\beta=$ R.

It is assumed that nanoparticles concentration is distributed equally and the nanofluid layer is developed in accordance with a single phase model. The fluid is a water based nanofluid containing five different types of nanoparticles: $\mathrm{Ag}, \mathrm{Cu}, \mathrm{CuO}, \mathrm{Al}_{2} \mathrm{O}_{3}$, and $\mathrm{TiO}_{2}$, whose thermo physical properties are outlined in Table 1. Together with the energy equation, the full mathematical model including the boundary conditions is given in the motion through the annulus by the single phase system [39]

$$
\begin{aligned}
\frac{1}{r} \frac{d}{d r}\left(r \mu_{n f} \frac{d u}{d r}\right) & =p_{x}\left(\rho c_{p}\right)_{n f} u \frac{\partial T}{\partial x}=\frac{1}{r} \frac{d}{d r}\left(r k_{n f} \frac{\partial T}{\partial r}\right), \\
u & =\bar{\lambda}_{1} \frac{d u}{d r} a t r=r_{i}, u=-\bar{\lambda}_{2} \frac{d u}{d r} \operatorname{atr}=r_{o}, \\
\frac{\partial T}{\partial r} & =0\left(\operatorname{ork}_{n f} \frac{\partial T}{\partial r}=q\right) \text { atr }=r_{i}, \\
k_{n f} \frac{\partial T}{\partial r} & =q\left(\text { or } \frac{\partial T}{\partial r}=0\right) \text { atr }=r,
\end{aligned}
$$


where $u$ is the velocity along the $r$-direction, $T$ is the local temperature and $p$ is the pressure. $\lambda_{1}$ and $\lambda_{2}$ are the slip velocity factors, the subscript $n f$ stands for the nanofluid property, and additionally the nanofluid properties appearing in Eq. (2.1) are respectively [39],

$$
\begin{aligned}
& \mu_{n f}=(1-\varphi)^{-2.5} \mu_{f}, \\
& \rho_{n f}=(1-\varphi) \rho_{f}+\varphi \rho_{s}, \\
& k_{n f}=k_{f} \frac{k_{s}+2 k_{f}-2 \varphi\left(k_{f}-k_{s}\right)}{k_{s}+2 k_{f}+\varphi\left(k_{f}-k_{s}\right)}
\end{aligned}
$$

with $\phi$ the solid volume fraction or concentration, $\rho_{f}$ and $\rho_{s}$ the densities of the pure fluid and nanoparticle, $k_{f}$ and $k_{s}$ are the thermal conductivities of the base fluid and nanoparticle, respectively, and $c_{p}$ is the heat capacitance.
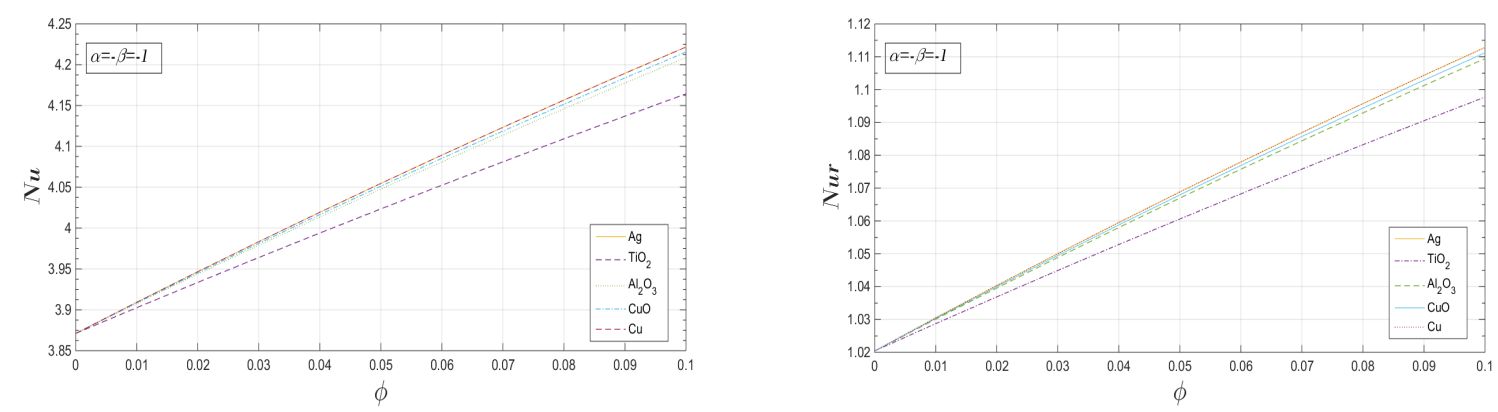

Figure 9: Nusselt numbers when $R=0.2, \phi=0.03$ for constant outer heat flux $\alpha=-\beta=-1$.
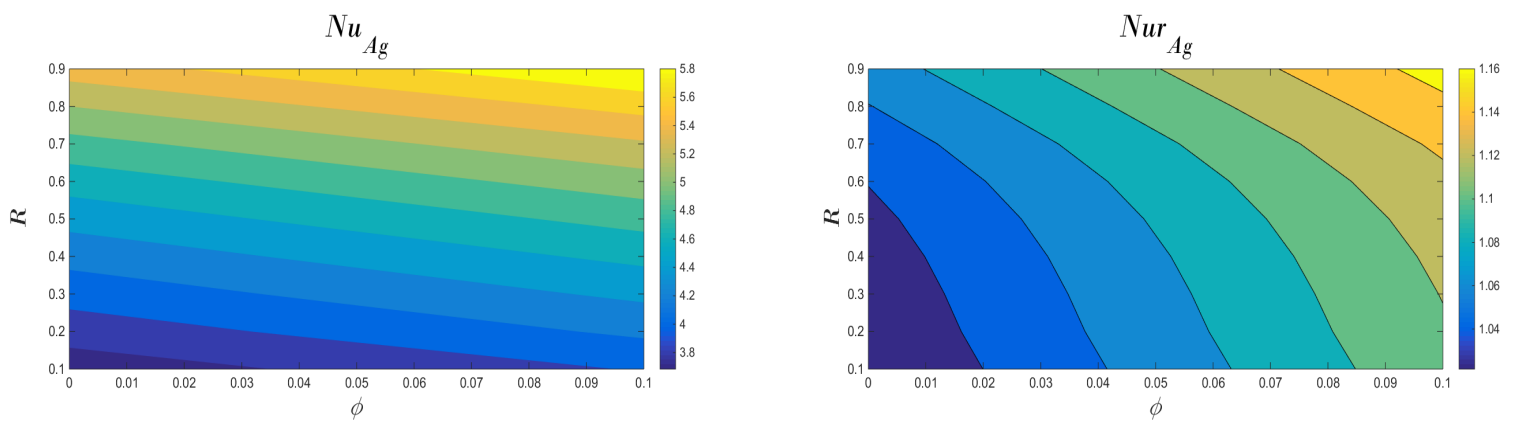

Figure 10: Nusselt numbers for Ag when $\lambda_{1}=\lambda_{2}=0.05$ for constant outer heat flux $\alpha=-\beta=-1$.
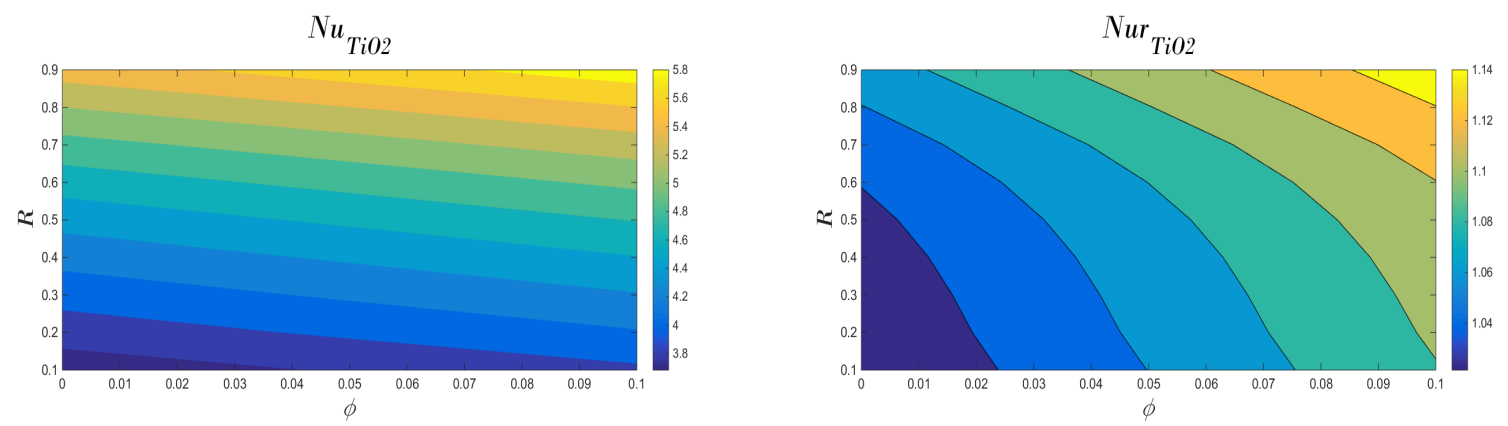

Figure 11: Nusselt numbers for $\mathrm{TiO}_{2}$ when $\lambda_{1}=\lambda_{2}=0.05$ for constant outer heat flux $\alpha=-\beta=-1$. 

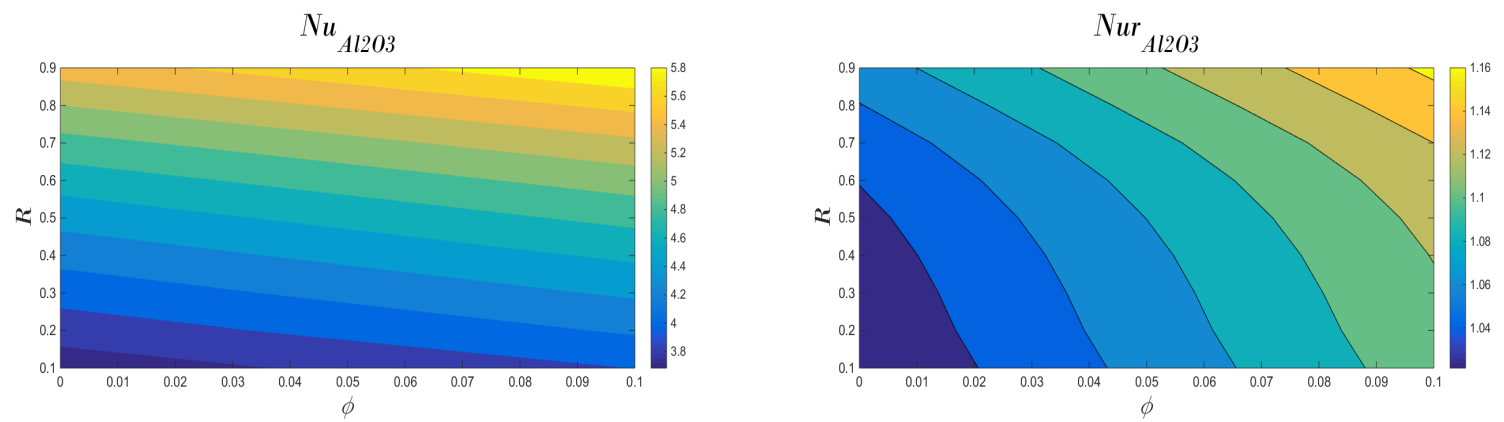

Figure 12: Nusselt numbers for $\mathrm{Al}_{2} \mathrm{O}_{3}$ when $\lambda_{1}=\lambda_{2}=0.05$ for constant outer heat flux $\alpha=-\beta=-1$.
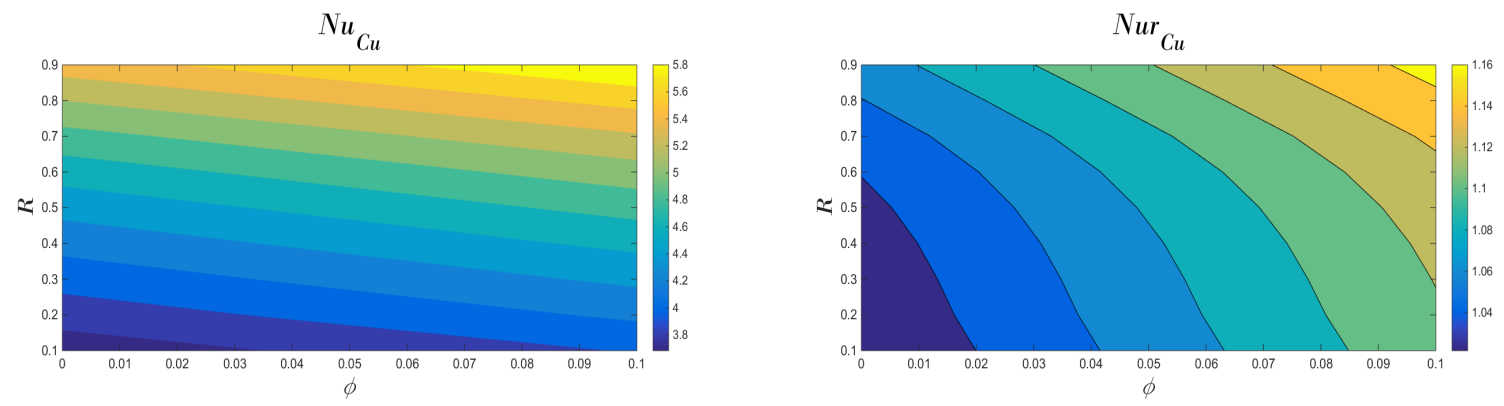

Figure 13: Nusselt numbers for $\mathrm{Cu}$ when $\lambda_{1}=\lambda_{2}=0.05$ for constant outer heat flux $\alpha=-\beta=-1$.
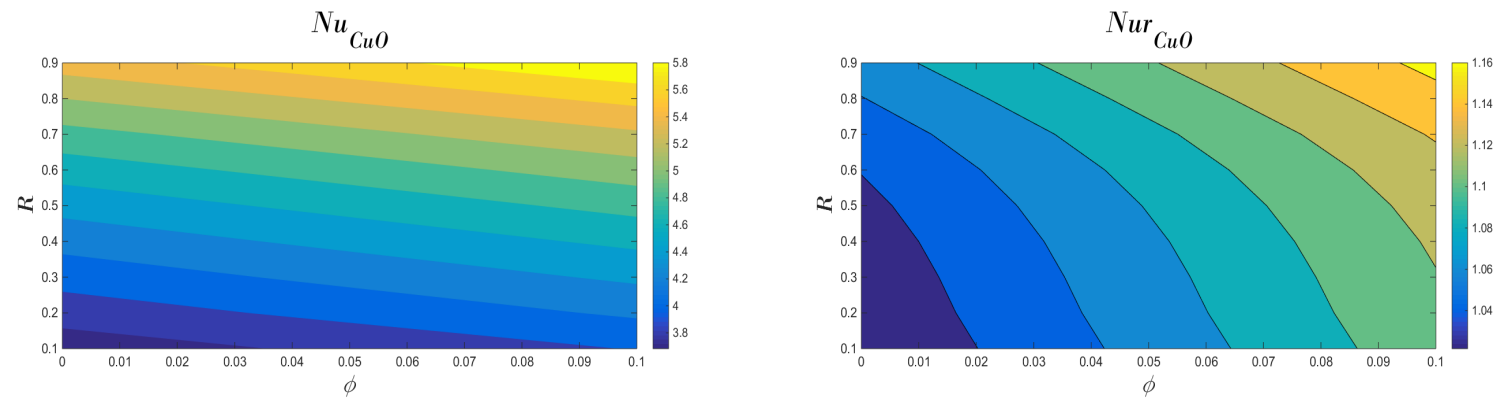

Figure 14: Nusselt numbers for $\mathrm{CuO}$ when $\lambda_{1}=\lambda_{2}=0.05$ for constant outer heat flux $\alpha=-\beta=-1$.

It should be reminded that the effective thermal conductivity of the nanofluid $k_{n f}$ approximated as above is due to Maxwell-Garnett model. It is also noted that the velocity slip given in Eq. (2.1) is due to both the base fluid and the nanoparticle, which was already explained in [39]. By defining the mean velocity as $\left(u_{m}=\int_{r_{i}}^{r_{o}}\right.$ rudr) and integrating the energy equation (Eq. (2.1)) a constant mean temperature gradient will be obtained [39] and by introducing the following transformation

$$
u=\frac{1}{\mu_{n f}}\left(-p_{x}\right) r_{o}^{2} U, T=T_{w}-\frac{r_{0} q}{k_{n f}} \theta, \eta=\frac{r}{r_{o}}, R=\frac{r_{i}}{r_{o}}, \lambda_{1}=\frac{\bar{\lambda}_{1}}{r_{o}}, \lambda_{2}=\frac{\bar{\lambda}_{2}}{r_{o}},
$$

Eq. (2.1) will be transferred to

$$
\begin{aligned}
& \frac{1}{\eta} \frac{d}{d \eta}\left(\eta \frac{d U}{d \eta}\right)=-1, \quad U(R)=\lambda_{1} \frac{d U(R)}{d \eta}, \quad u(1)=-\lambda_{2} \frac{d U(1)}{d \eta}, \\
& \frac{1}{\eta} \frac{d}{d \eta}\left(\eta \frac{d \theta}{d \eta}\right)=\alpha \frac{U}{u_{m}}, \quad \theta(\beta)=0, \quad \frac{d \theta(\beta)}{d \eta}=-1
\end{aligned}
$$


It should be noticed that the energy equation in last equation is combined into a single form such that for the constant outer heat flux $\alpha=-\beta=-1$ and for the constant inner heat flux $\alpha=\beta=R$, respectively. In both thermal conditions the local Nusselt number $\mathrm{Nu}$ is given by

$$
\mathrm{Nu}=\frac{2(1-R)}{k_{f}\left(T_{w}-T_{b}\right)}=\frac{k_{n f}}{k_{f}} \frac{2(1-R)}{\theta_{b}},
$$

which $T_{b}$ is the bulk mean temperature whose dimensionless form is defined by

$$
\theta_{\mathrm{b}}=\frac{\int_{\mathrm{R}}^{1} \eta \mathrm{U} \theta \mathrm{d} \eta}{\int_{\mathrm{R}}^{1} \eta \mathrm{Ud} \eta} .
$$

To measure the relative effects of velocity slip $\lambda$ on the rate of heat transfer, Nur is defined

$$
\text { Nur }=\frac{k_{\mathrm{nf}}}{k_{\mathrm{f}}} \frac{\left.\theta_{\mathrm{b}}\right|_{\lambda=0}}{\theta_{\mathrm{b}}}
$$

which is normalized by the Nusselt number (Eq. (2.4)) in the absence of slip, that is $\lambda=0$.

It should be noted that the obtained velocity and temperature fields depend upon the concentration $\phi$ of nanofluids, so $u^{*}$ is defined as following graph for depicting the figures

$$
u^{*}=\frac{(1-\varphi)^{5 / 2 u}}{2 u_{m}} \text {. }
$$

\section{Least square method (LSM)}

For conception the main idea of LSM, a differential operator D is acted on a function $u$ to produce a function $p$ [34]:

$$
\begin{aligned}
D(u(x)) & =p(x), \\
\mathfrak{u} \cong \tilde{u} & =\sum_{i=1}^{n} c_{i} \varphi_{i} .
\end{aligned}
$$

Now, when substituted into the differential operator, D, the result of the operations generally is not $p(x)$. Hence an error or residual will exist:

$$
\mathrm{R}(\mathrm{x})=\mathrm{D}(\tilde{\mathrm{u}}(\mathrm{x}))-\mathrm{p}(\mathrm{x}) \neq 0 .
$$

The main concept in WRMs is to force the residual to zero in some average sense over the domain. That is,

$$
\int_{X} R(x) W_{i}(x)=0 \quad i=1,2, \ldots, n,
$$

where $W_{i}$, the number of weight functions, is exactly equal to the number of unknown constants $c_{i}$ in $\tilde{u}$. If the continuous summation of all the squared residuals is minimized, the rationale behind the name can be seen. In other words, a minimum of

$$
S=\int_{X} R(x) R(x) d x=\int_{X} R^{2}(x) d x .
$$

In order to achieve a minimum of this scalar function, the derivatives of $S$ with respect to all the unknown parameters must be zero. That is,

$$
\frac{\partial S}{\partial c_{i}}=2 \int_{x} R(x) \frac{\partial R}{\partial c_{i}} d x=0 .
$$


Comparing with Eq. (3.1), the weight functions are seen to be

$$
W_{i}=2 \frac{\partial R}{\partial c_{i}}
$$

However, the "2" coefficient can be dropped, since it cancels out in the equation. Therefore the weight functions for the Least Squares Method are just the derivatives of the residual with respect to the unknown constants [34],

$$
W_{i}=\frac{\partial R}{\partial c_{i}}
$$

\section{Results and discussions}

As mentioned before, one of the main goals of this study is finding the solution of governing equation of hydro-thermally nanofluilds in between concentric pipes. Regarding to BCs and Eqs. (2.3), it is assumed the following expressions for $\lambda_{1}=\lambda_{2}=0$ :

$$
\begin{aligned}
u(\eta)= & a_{0}(\eta-R)(\eta-1)+a_{1}(\eta-R)^{2}(\eta-1)+a_{2}(\eta-R)(\eta-1)^{2}+a_{3}(\eta-R)^{2}(\eta-1)^{2} \\
& +a_{4}(\eta-R)^{3}(\eta-1)^{2}+a_{5}(\eta-R)^{2}(\eta-1)^{3}, \\
\theta(\eta)= & -(\eta-\beta)+a_{6} \eta(\eta-\beta)^{2}+a_{7} \eta(\eta-\beta)^{3}+a_{8} \eta(\eta-\beta)^{4}+a_{9} \eta(\eta-\beta)^{5}+a_{10} \eta(\eta-\beta)^{6} .
\end{aligned}
$$

By computing the values of $a_{i}, i=0,1, \ldots, 10$, the approximate solution of the problem will be obtained. For example when $\lambda_{1}=\lambda_{2}=0, R=0.5, \alpha=-1$, and $\beta=1$

$$
\begin{aligned}
U(\eta)= & -0.30209(\eta-R)(\eta-1)-0.31379(\eta-R)^{2}(\eta-1)+0.55978(\eta-R)(\eta-1)^{2} \\
& -0.90590(\eta-R)^{2}(\eta-1)^{2}+1.43708(\eta-R)^{3}(\eta-1)^{2}-1.18040(\eta-R)^{2}(\eta-1)^{3} .
\end{aligned}
$$

These results are compared with the numerical solution of problem which obtained by Maple in the Table 2. As seen in this table, LSM results are in good-excellent with low percentage errors (averagely $0.03 \%$ error) compared to numerical solution.

Table 2: Comparison of LSM results with the numerical solution for $\lambda_{1}=\lambda_{2}=0, R=0.5, \alpha=-1, \beta=1$.

\begin{tabular}{lllllll}
\hline$\eta$ & & $\mathrm{U}(\eta)$ & \multicolumn{3}{c}{$\mathrm{U}^{\prime}(\eta)$} \\
\hline & Numerical & LSM (Eq. (2.2)) & Error (\%) & Numerical & LSM & Error (\%) \\
0.50 & 0.0 & 0.0 & 0.0 & 0.291010 & 0.290994 & 0.00549 \\
0.55 & 0.012656 & 0.012664 & 0.06321 & 0.216827 & 0.216810 & 0.00784 \\
0.60 & 0.021818 & 0.021831 & 0.05958 & 0.150842 & 0.150822 & 0.01325 \\
0.65 & 0.027845 & 0.027853 & 0.02873 & 0.091126 & 0.091103 & 0.02524 \\
0.70 & 0.031075 & 0.031015 & 0.19308 & 0.036457 & 0.036412 & 0.12343 \\
0.75 & 0.031555 & 0.031548 & 0.02218 & -0.014365 & -0.014351 & 0.09745 \\
0.80 & 0.029638 & 0.029632 & 0.02024 & -0.061864 & -0.061832 & 0.05172 \\
0.85 & 0.025412 & 0.025411 & 0.00393 & -0.106751 & -0.106717 & 0.03185 \\
0.90 & 0.018999 & 0.019002 & 0.01579 & -0.149437 & -0.149401 & 0.02409 \\
0.95 & 0.010499 & 0.010503 & 0.03810 & -0.190257 & -0.190210 & 0.02470 \\
1 & 0.0 & 0.0 & 0.0 & -0.229458 & -0.229409 & 0.02135 \\
\hline
\end{tabular}

Fig. 2 shows the $u^{*}$ profile to show the effect of nanoparticles volume fraction. As seen, by increasing the $\phi$, maximum velocity profile reduces due to higher viscosity of nanofluids. Effect of $R\left(\frac{r_{i}}{r_{o}}\right)$ on the velocity profile is presented in Fig. 3. Increasing the $R$ (by this assumption that $r_{o}$ is constant) means that inlet radius increased and so the distance between the pipes reduced which makes larger maximum 
velocity in the profile as confirmed in Fig. 3 for yellow line $(R=0.9)$. To demonstrate the effect of slip conditions, Fig. 4 is presented and reveals that larger slip conditions makes flatten the velocity profiles by bringing the peaks down, the momentum boundary layer thickness is predicted to be much reduced as reported in [39]. In Fig. 5 the influence of $\lambda_{2}$ on $u^{*}$ profile is studied separately.

Thermal boundary layers in this study are presented in Figs. 6-8 to show the effect of various parameters on it. Fig. 6 demonstrates the radii ratio $(R)$ on the temperature profile for constant outer heat flux $\alpha=-\beta=-1$ and constant inner heat flux $\alpha=\beta=R$ for $\mathrm{Cu}$-water nanofluid. For example when the outer wall is in constant heat flux, by increasing the $R$, the distance between the pipes reduces and more heat transfers to nanofluids from the wall which makes smaller difference between wall temperature and nanofluid temperature, i.e., smaller $\theta$.

Fig. 7 confirms that by permitting a small velocity slip, thermal boundary layer thicknesses reduces for the case of constant heat flux on outer wall. Fig. 8 also confirms the same treatment in different slip conditions of outer wall.

Figs. 9-14 are related to the Nusselt and normalized Nusselt number to show the effect of nanoparticles on the heat transfer as well as their volume fraction and other parameters such as $R$. The first observation from these figures is that suspended nanoparticles effectively increase the rate of heat transfer from the wall to the fluid, Fig. 9 shows that the maximum Nusselt numbers (and consequently maximum heat transfer) occurs for $\mathrm{Ag}$ and then $\mathrm{Cu}$ nanoparticle due to their larger thermal conductivity among other nanoparticles and the minimum Nusselt number is recorded for $\mathrm{TiO}_{2}$ because of weak thermal conductivity. Contour plots of Figs. 10,11, 12, 13, and 14 are presented to graphically show the effect of $\mathrm{R}$ and $\phi$ simultaneously on the Nusslet and normalized Nusselt number for $\mathrm{Ag}, \mathrm{TiO}_{2}, \mathrm{Al}_{2} \mathrm{O}_{3}, \mathrm{Cu}$, and $\mathrm{CuO}$, respectively. By the previous explanations, it is evident that in all nanoparticles increasing the both $R$ and $\phi$ enhances the heat transfer process and make larger Nusselt numbers as seen in the graphs.

\section{Conclusion}

In this paper, analytical least square method (LSM) is applied to find the hydro-thermally treatment of nanofluids flow between concentric heat pipes. The pipe walls are permitted to carry different and opposite slip velocities of nanofluids and they are either preserved at constant heat flux of outer wall with the inner wall insulated or vice versa. For this study, five distinct types of nanoparticles: $\mathrm{Ag}, \mathrm{Cu}$, Cuo, $\mathrm{Al}_{2} \mathrm{O}_{3}$, and $\mathrm{TiO}_{2}$ were suspended in water and the effect of volume fractions, Radii ratio (R) and slip parameter $(\lambda)$ on velocity/temperature profiles is discussed as well as Nusselt numbers. As an outcome, by increasing the $R$, the distance between the pipes will reduce and more heat will transfer to nanofluids from the wall under the heat flux, so it makes larger Nusselt number.

\section{Acknowledgment}

The authors gratefully acknowledge the financial support of the National Natural Science Foundation of China (No. 51422604, 21276206) and the National 863 Program of China (No. 2013AA050402). This work was also supported by the China Fundamental Research Funds for the Central Universities.

\section{References}

[1] A. R. Ahmadi, A. Zahmatkesh, M. Hatami, D. D. Ganji, A comprehensive analysis of the flow and heat transfer for a nanofluid over an unsteady stretching flat plate, Powder Technol., 258 (2014), 125-133. 1

[2] N. S. Akbar, M. Raza, R. Ellahi, Copper oxide nanoparticles analysis with water as base fluid for peristaltic flow in permeable tube with heat transfer, Compu. Methods Programs Biomed., 130 (2016), 22-30. 1

[3] M. Akbarzadeh, S. Rashidi, M. Bovand, R. Ellahi, A sensitivity analysis on thermal and pumping power for the flow of nanofluid inside a wavy channel, J. Mol. Liq., 220 (2016), 1-13. 1

[4] M. M. Bhatti, T. Abbas, M. M. Rashidi, Effects of thermal radiation and electromagnetohydrodynamic on viscous nanofluid through a riga plate, Multidiscip. Model. Mater. Struct., 12 (2016), 605-618. 1 
[5] M. M. Bhatti, T. Abbas, M. M. Rashidi, M. E. S. Ali, Numerical simulation of entropy generation with thermal radiation on MHD Carreau nanofluid towards a shrinking sheet, Entropy, 18 (2016), 14 pages.

[6] M. M. Bhatti, M. M. Rashidi, Effects of thermo-diffusion and thermal radiation on Williamson nanofluid over a porous shrinking/stretching sheet, J. Mol. Liq., 221 (2016), 567-573. 1

[7] M. Bovand, S. Rashidi, G. Ahmadi, J. A. Esfahani, Effects of trap and reflect particle boundary conditions on particle transport and convective heat transfer for duct flow-A two-way coupling of Eulerian-Lagrangian model, Appl. Therm. Eng., 108 (2016), 368-377. 1

[8] A. S. Dogonchi, M. Hatami, G. Domairry, Motion analysis of a spherical solid particle in plane Couette Newtonian fluid flow, Powder Technol., 274 (2015), 186-192. 1

[9] G. Domairry, A. Aziz, Approximate analysis of MHD squeeze flow between two parallel disks with suction or injection by homotopy perturbation method, Math. Probl. Eng., 2009 (2009), 19 pages. 1

[10] G. Domairry, M. Hatami, Squeezing Cu-water nanofluid flow analysis between parallel plates by DTM-Padé Method, J. Mol. Liq., 193 (2014), 37-44. 1

[11] R. Ellahi, M. Hassan, A. Zeeshan, Shape effects of nanosize particles in $\mathrm{Cu}-\mathrm{H} 2 \mathrm{O}$ nanofluid on entropy generation, Int. J. Heat Mass Transf., 81 (2015), 449-456. 1

[12] R. Ellahi, M. Hassan, A. Zeeshan, Aggregation effects on water base nano fluid over permeable wedge in mixed convection, Asia Pac. J. Chem. Eng., 11 (2016), 179-186. 1

[13] M. Fakour, A. Vahabzadeh, D. D. Ganji, M. Hatami, Analytical study of micropolar fluid flow and heat transfer in a channel with permeable walls, J. Mol. Liq., 204 (2015), 198-204. 1

[14] S.-Q. Gao, H.-Y. Duan, Negative norm least-squares methods for the incompressible magnetohydrodynamic equations, Acta Math. Sci. Ser. B Engl. Ed., 28 (2008), 675-684. 1

[15] S. E. Ghasemi, M. Hatami, G. R. M. Ahangar, D. D. Ganji, Electrohydrodynamic flow analysis in a circular cylindrical conduit using least square method, J. Electrostat., 72 (2014), 47-52. 1

[16] S. E. Ghasemi, M. Hatami, D. D. Ganji, Thermal analysis of convective fin with temperature-dependent thermal conductivity and heat generation, Case Stud. Therm. Eng., 4 (2014), 1-8. 1

[17] S. E. Ghasemi, M. Hatami, A. K. Sarokolaie, D. D. Ganji, Study on blood flow containing nanoparticles through porous arteries in presence of magnetic field using analytical methods, Phys. E Low Dimens. Syst. Nanostruct., 70 (2015), 146-156. 1

[18] S. E. Ghasemi, P. Valipour, M. Hatami, D. D. Ganji, Heat transfer study on solid and porous convective fins with temperature-dependent heat generation using efficient analytical method, J. Cent. South Univ., 21 (2014), 4592-4598. 1

[19] S. Göktepe, K. Atalık, H. Ertürk, Comparison of single and two-phase models for nanofluid convection at the entrance of a uniformly heated tube, Int. J. Thermal Sci., 80 (2014), 83-92. 1

[20] M. Haghshenas Fard, M. Nasr Esfahany, M. R. Talaie, Numerical study of convective heat transfer of nanofluids in a circular tube two-phase model versus single-phase model, Int. Commun. Heat Mass Transf., 37 (2010), 91-97. 1

[21] M. Hatami, G. R. M. Ahangar, D. D. Ganji, K. Boubaker, Refrigeration efficiency analysis for fully wet semi-spherical porous fins, Energy Convers. Manage., 84 (2014), 533-540. 1

[22] M. Hatami, G. Domairry, Transient vertically motion of a soluble particle in a Newtonian fluid media, Powder Technol., 253 (2014), 481-485. 1

[23] M. Hatami, D. D. Ganji, Investigation of refrigeration efficiency for fully wet circular porous fins with variable sections by combined heat and mass transfer analysis, Int. J. Refrig., 40 (2014), 140-151. 1

[24] M. Hatami, D. D. Ganji, Motion of a spherical particle in a fluid forced vortex by DQM and DTM, Particuology, 16 (2014), 206-212. 1

[25] M. Hatami, D. D. Ganji, Motion of a spherical particle on a rotating parabola using Lagrangian and high accuracy multistep differential transformation method, Powder Technol., 258 (2014), 94-98. 1

[26] M. Hatami, D. D. Ganji, Natural convection of sodium alginate (SA) non-Newtonian nanofluid flow between two vertical flat plates by analytical and numerical methods, Case Stud. Therm. Eng., 2 (2014), 14-22. 1

[27] M. Hatami, D. D. Ganji, Thermal behavior of longitudinal convectiveradiative porous fins with different section shapes and ceramic materials ( $\mathrm{SiC}$ and $\mathrm{Si}_{3} \mathrm{~N}_{4}$ ), Ceram. Int., 40 (2014), 6765-6775. 1

[28] M. Hatami, H. Safari, Effect of inside heated cylinder on the natural convection heat transfer of nanofluids in a wavy-wall enclosure, Int. J. Heat Mass Transf., 103 (2016), 1053-1057. 1

[29] T. Hayat, M. Imtiaz, A. Alsaedi, M. A. Kutbi, MHD three-dimensional flow of nanofluid with velocity slip and nonlinear thermal radiation, J. Magn. Magn. Mater., 396 (2015), 31-37. 1

[30] J. A. Khan, M. Mustafa, T. Hayat, A. Alsaedi, Three-dimensional flow of nanofluid over a non-linearly stretching sheet: an application to solar energy, Int. J. Heat. Mass. Transf., 86 (2015), 158-164. 1

[31] P. Krajnik, F. Pusavec, A. Rashid, Nanofluids: Properties, applications and sustainability aspects in materials processing technologies, Advances in Sustainable Manufacturing, Springer, Berlin, (2011), 107-113. 1

[32] R. P. Laein, S. Rashidi, J. A. Esfahani, Experimental investigation of nanofluid free convection over the vertical and horizontal flat plates with uniform heat flux by PIV, Adv. Powder Technol., 27 (2016), 312-322. 1

[33] S. T. Mohyud-Din, Z. A. Zaidi, U. Khan, N. Ahmed, On heat and mass transfer analysis for the flow of a nanofluid between rotating parallel plates, Aerosp. Sci. Technol., 46 (2015), 514-522. 1

[34] M. N. Özişik, Heat conduction, second edition, John Wiley \& Sons Inc., New York, (1993). 1, 3, 3

[35] P. Rana, R. Bhargava, Flow and heat transfer of a nanofluid over a nonlinearly stretching sheet: a numerical study, 
Commun. Nonlinear Sci. Numer. Simul., 17 (2012), 212-226. 1

[36] M. M. Rashidi, N. Freidoonimehr, A. Hosseini, O. A. Bég, T.-K. Hung, Homotopy simulation of nanofluid dynamics from a non-linearly stretching isothermal permeable sheet with transpiration, Meccanica, 49 (2014), 469-482. 1

[37] R. H. Stern, H. Rasmussen, Left ventricular ejection: model solution by collocation, an approximate analytical method, Comput. Biol. Med., 26 (1996), 255-261. 1

[38] M. Turkyilmazoglu, Analytical solutions of single and multi-phase models for the condensation of nanofluid film flow and heat transfer, Eur. J. Mech. B/Fluid., 53 (2015), 272-277. 1

[39] M. Turkyilmazoglu, Anomalous heat transfer enhancement by slip due to nanofluids in circular concentric pipes, Int. J. Heat Mass Transf., 85 (2015), 609-614. 1, 1, 1, 2, 2, 2, 4

[40] B. Vaferi, V. Salimi, D. D. Baniani, A. Jahanmiri, S. Khedri, Prediction of transient pressure response in the petroleum reservoirs using orthogonal collocation, J. Petrol. Sci. Eng., 98 (2012), 156-163. 1 